\title{
Numerical simulations of forest fire propagation and smoke transport as an external hazard assessment methodology development for a nuclear power plant
}

\author{
Yasushi OKANO* and Hidemasa YAMANO* \\ *Japan Atomic Energy Agency \\ 4002 Narita-cho, Oarai, Ibaraki 311-1393, Japan \\ E-mail: okano.yasushi@jaea.go.jp
}

Received 27 October 2015

\begin{abstract}
A new method has been developed to assess potential challenges by forest fire smoke on a cooling function of a decay heat removal system (DHRS) of a sodium-cooled fast reactor. Combinational numerical simulations of a forest fire propagation and a smoke transport were performed to evaluate a cumulative amount of smoke captured on air filters of the DHRS. The forest fire propagation simulations were performed using FARSITE code to evaluate a temporal increase of a forest fire spread area, a frontal fireline location, reaction intensity, and fireline intensity. Peripheral boundary of the forest fire spread area is shaped like an ellipse on the terrain, and the active forest fire area from which smoke is produced as a forest fire product is increased with forest fire spread. The smoke transport simulations were performed using ALOFT-FT code where a spatial distribution of smoke density, especially of particle matter (PM), is evaluated. The snapshot (i.e. at a certain time step) outputs by FARSITE on the reaction intensity and the fireline intensity were utilized as the input data for ALOFT-FT, while it was conservatively assumed that the smoke generated from the active forest fire area along the periphery boundary rises up from the frontal fireline location nearest to a nuclear power plant (NPP) and that prevailing wind transports all smoke to an NPP in the leeward side. The evaluated time-dependent changes of spatial PM density were utilized to calculate a cumulative amount of PM captured on the air filters of the DHRS. Sensitivity analysis was performed on prevailing wind speed to which both the fireline intensity and the smoke transport behavior are sensitive. The total amount of PM on the air filters was conservatively estimated around several hundred grams per $\mathrm{m}^{2}$ which is well below the utilization limit.
\end{abstract}

Key words : Forest fire, External hazard, Smoke, Particle matter, Air filter, Decay heat removal system, Sodium cooled fast reactor, FARSITE, ALOFT-FT

\section{Introduction}

After the Fukushima Daiichi nuclear power plant (NPP) accidents, serious concerns are being raised on the safety of NPP against external hazards, one of which is a forest fire. In general, safety assessments on external hazards had been performed by a deterministic approach in which bounding initial and boundary conditions are given conservatively. According to a guide for external fire accidents by the regulation (Nuclear Regulation Authority, 2013), a general qualitative assessment is required on an effect of forest fire smoke on safety-related equipment, e.g. emergency diesel generator, although no recommendation is provided on a quantitative evaluation method. In order to assess appropriateness of measures against forest fire smoke, a quantitative method is indispensable to evaluate how much amount of smoke is produced by a forest fire, transported to an NPP, and accumulated in equipment.

In previous studies on an oil tank fire, smoke production and transport quantitative evaluations were performed using a numerical simulation code whose applicability was validated through a number of accidents and experiments on tank fire as examples by Yamada (1998) and by Rouil (2015). The numerical simulation code was applied as well to a smoke transport assessment of a cruise ship fire (Vairo, et al., 2015). In these previous studies, the smoke was assessed to be generated from a fixed location because the fire location does not move during the simulated durations. The applicability of a numerical simulation for a smoke transport of a forest fire was indicated (Sandberg, et al., 2002), and the previous 
studies mainly focused on large forest fire effects on an atmosphere system; e.g. stratosphere system (Trentmann, et al., 2006), and country-wide spreads of smoke and gaseous emissions (Pouliot, et al., 2005) (Nuryanto, 2015). As a special feature of a forest fire different from oil and ship fires, the smoke generation area moves due to the fire propagation and spread, and a forest fire intensity varies with local vegetation and topographical conditions. A coupling of forest fire behavior and smoke transport was applied for developing a forest fire forecast tool in a limited number of previous studies where a coarse grid was utilized (e.g. square kilometer resolutions) to deal with a brief behavior in country-wide large area (Kochanski, et al., 2013).

In order to deal with a forest fire spread around an NPP, detail resolution on a terrain with enhancing local vegetation and topographical features, e.g. deciduous tree forest and paddy fields, and mountains/hills near to a seashore, are necessary to be incorporated in a quantitative assessment. In order to assess the effect on an NPP, not only smoke spatial distribution near an NPP but also a numerical model for evaluating a cumulative amount of smoke captured in NPP equipment, e.g. air filter of a decay heat removal system (DHRS), are necessary to be incorporated. In this study, a new method was developed to evaluate a forest fire smoke production and transport behavior in accordance with the forest fire propagation around an NPP and also to evaluate a cumulative smoke in air filters of a DHRS. Sensitivity study to weather conditions especially on prevailing wind speed (PWS) was performed to assess the air filter integrity during the forest fire. The smoke spatial density near an NPP site was estimated as well for assessing accident management capability under forest fire approaching situation.

\section{Framework of smoke transport analyses as a forest fire hazard assessment methodology 2.1 Forest fire hazard intensity parameters}

Phenomena during a forest fire (Forest Fire Control Association, 2007) outside an NPP are caused by heat, flame, smoke, and flying spark. The relation among the physical phenomena, forest fire intensity and key parameters, potential consequences, and potential direct/indirect challenges on an NPP are summarized in Fig. 1. Challenges due to "smoke" and "flying spark" might arise even the forest fire is away from, whereas challenges due to "heat" and "flame" might arise only when a forest fire is near an NPP site. The smoke would directly affect air filters of the DHRS and indirectly affect visibility needed for accident management actions in/near the NPP site. The flying sparks generate spot fires and may shorten the grace period for preparation of accident management. The direct effects by radiation and convection heat would affect structures in an NPP site (e.g. external fuel tank).

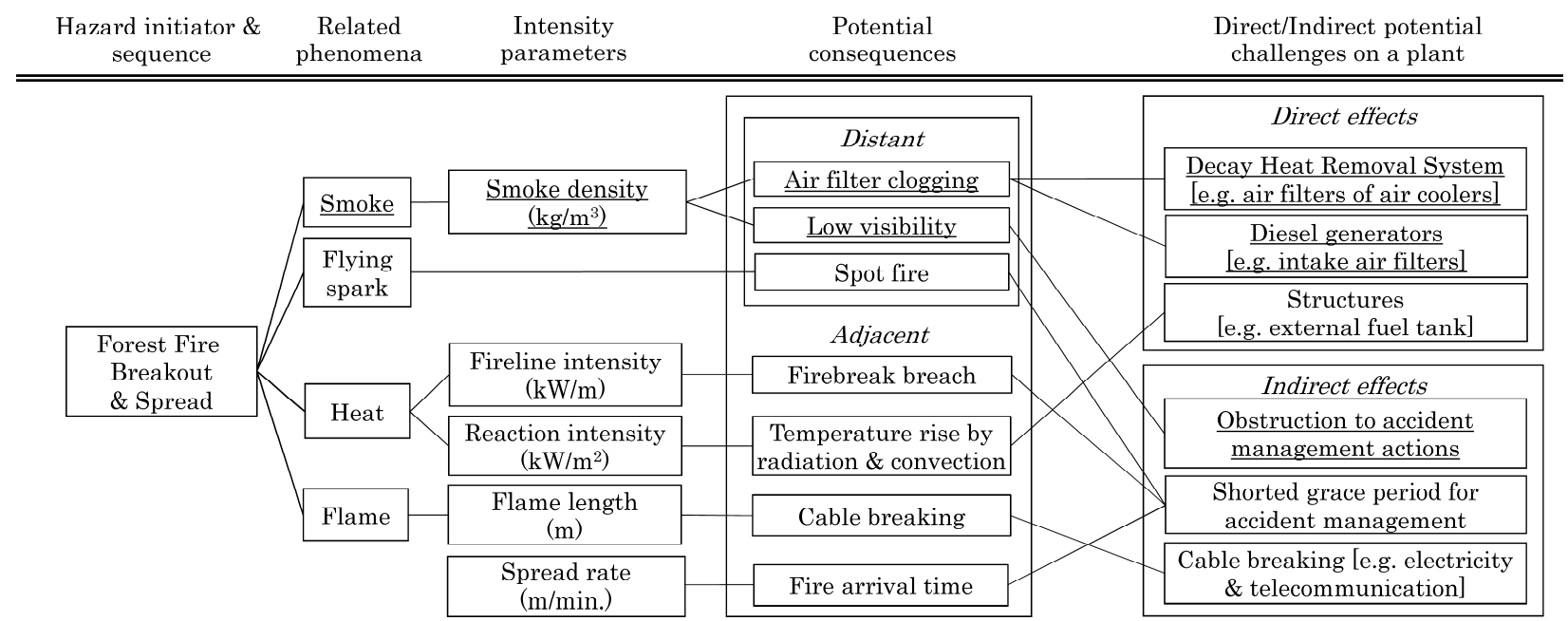

Fig. 1 Relationship among hazard initiator and sequence, forest fire related phenomena and intensity parameters, and potential consequences and challenges on a nuclear power plant. Potential consequences are categorized into distant and adjacent effects, and potential challenges are categorized into direct and indirect effects on the plant. Smoke related parameters, consequences and challenges are underlined. The potential challenges are related to air filter clogging and visibility needed for accident management actions. 
Cables for electricity and telecommunication would be broken if the flame reaches. In this study, the smoke effects on an air filter of a DHRS and visibility are specifically assessed, and a particle matter (PM) is dealt with as a representative of forest fire smoke. The key parameters which represent the challenges by smoke are "spatial density of PM" and "accumulated PM on an air filter of a DHRS".

\subsection{Framework of smoke production and transport analyses by numerical simulations}

In this study, combinational utilization of two simulation codes was applied where a forest fire propagation simulation is conducted first by the "Fire Area Simulator" (FARSITE) (Finney, 2004) and smoke transport simulation is then performed by "A Large Outdoor Fire plume Trajectory model - Flat Terrain” (ALOFT-FT) (McGrattan, et al., 1993). A procedure of these analyses on forest fire propagation, smoke generation and transportation, and cumulative amount of smoke calculation is illustrated in Fig. 2. The initial and boundary conditions and the relation between inputs and outputs of simulations and calculations are summarized in Fig. 3.

A temporal increase of a forest fire spread area and a frontal fireline location are obtained by the FARSITE simulation, and "reaction intensity (unit in $\mathrm{kW} / \mathrm{m}^{2}$ )" and frontal "fireline intensity (unit in $\mathrm{kW} / \mathrm{m}$ )" are obtained as well. The boundary of the forest fire spread area is shaped like an ellipse on the terrain, and the boundary length is increased with elapsed time of the forest fire spread. According to the previous study on the sensitivity analyses on weather conditions, the "spread rate" and frontal "fireline intensity" depend much on PWS and relative humidity (Okano and Yamano, 2014). FARSITE cannot evaluate how the particles spread into the atmosphere from an active forest fire area after passage of a frontal fireline. Hence, a model is developed in this study for estimating how much the smoke production rate is in accordance with the forest fire propagation simulation results. The spatial PM density is evaluated by PM transport simulation where the PM generated by a forest fire moves upward with rising air current by a plume and then horizontally advected by prevailing wind and diffused in air. The PM would cause the air filter clogging, hence a new model is developed as well to calculate "a cumulative amount of PM (unit in kg)" at the air filters of the DHRS from the simulation results by ALOFT-FT.

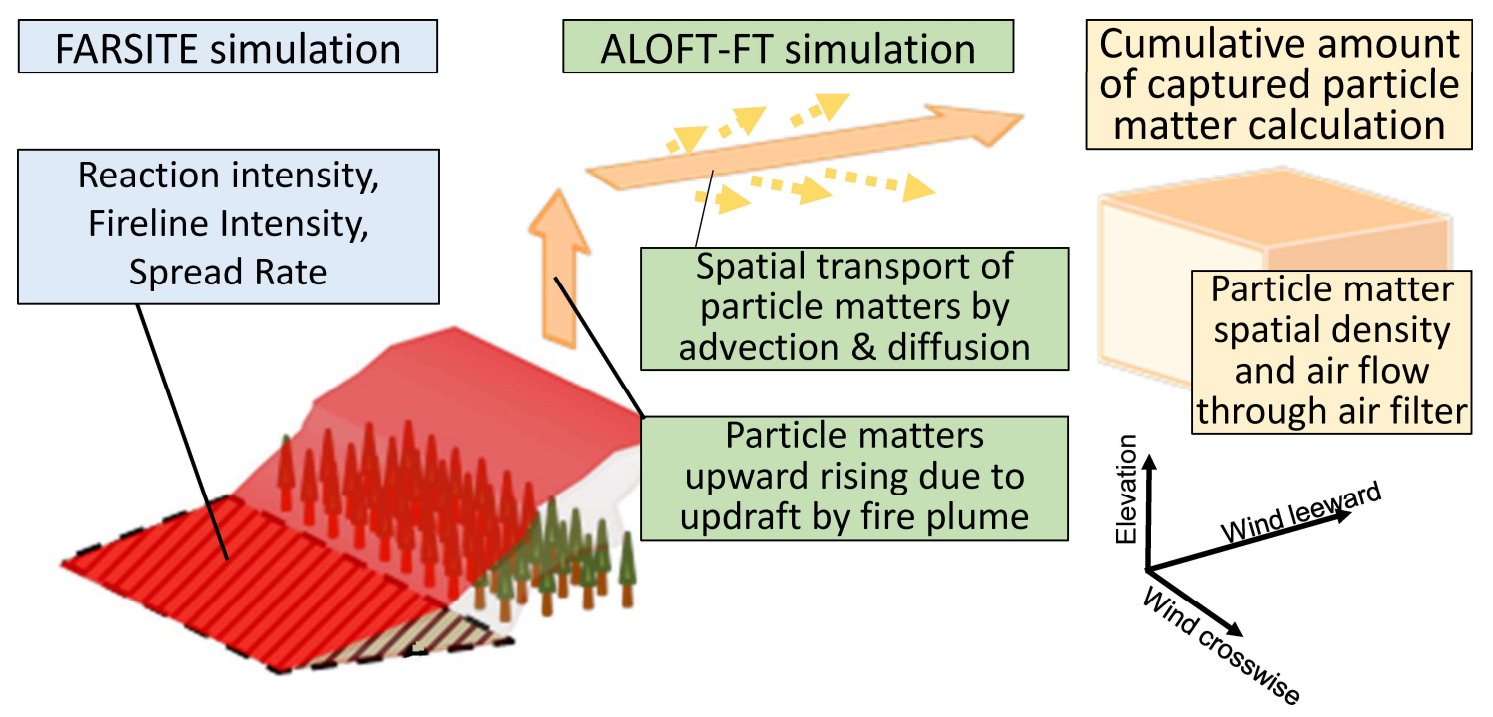

Fig. 2 Smoke production by a forest fire, transportation by fire plume and prevailing wind, and capture in air filters in a nuclear power plant. Reaction intensity, fireline intensity and spread rate are evaluated from FARSITE simulation, and the outputs are utilized for ALOFT-FT simulation where particle matter updraft by fire plume and spatial transport by advection and diffusion are evaluated. Cumulative amount of particle matter on air filters is calculated from the spatial particle matter density at the air intake location of a decay heat removal system. 
Boundary and Initial Conditions

\begin{tabular}{|l|}
\hline - Forest fire conditions \\
$\checkmark$ Breakout point \& time \\
- Weather conditions \\
$\checkmark$ Wind speed/direction \\
$\checkmark$ Temperature, Humidity \\
- Vegetation conditions \\
$\checkmark$ Map of tree species \\
$\checkmark$ Tree parameters \\
- Topography conditions \\
$\checkmark$ Elevation, Slope angle \\
$\checkmark$ Map of land use \\
\hline \hline - Weather conditions \\
$\checkmark$ Atmospheric stability \\
- Vegetation conditions \\
$\checkmark$ PM emission ratios \\
\hline Decay heat removal system \\
$\checkmark$ Air cooler intake heights \\
$\checkmark$ Area of air filters \\
$\checkmark$ Airflow velocity \\
\hline
\end{tabular}

Outputs of Forest Fire Propagation Simulation (FARSITE code)

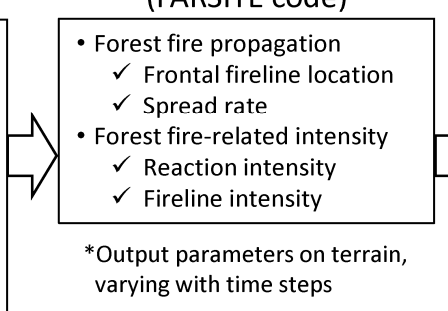

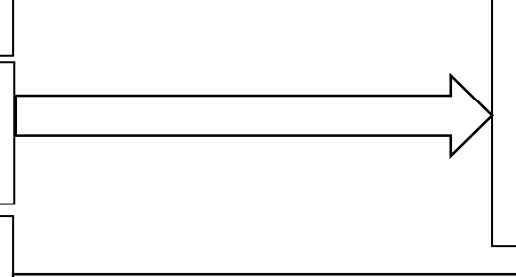

\section{Outputs of Smoke \\ Transport Simulation (ALOFT-FT code)}

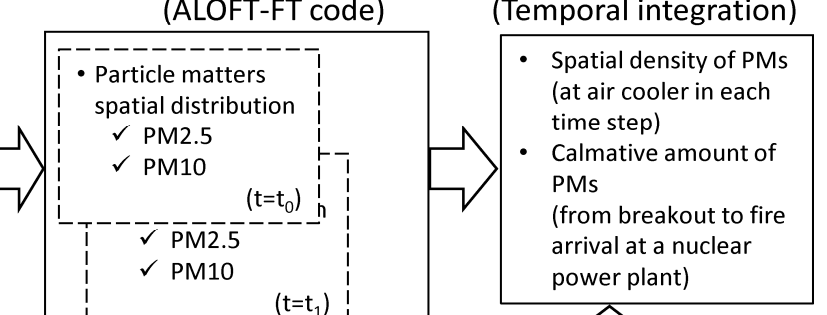
Captured PM Calculation (Temporal integration)

Fig. 3 Utilization of boundary and initial conditions on forest fire, weather, vegetation and topography, and transmission of outputs among forest fire propagation simulation by FARSITE, smoke transport simulation by ALOFT-FT and cumulative amount calculation. Output values at certain time steps by FARSITE are transmitted to ALOFT-FT. The snapshot particle matter spatial distributions are utilized in the cumulative amount calculation to which decay heat removal system characteristic parameters are given.

\section{Forest fire propagation simulations 3.1 FARSITE simulation cases and initial/boundary conditions}

The initial weather conditions for the FARSITE simulation is summarized in Table 1. According to weather database of a region nearby a sodium-cooled fast reactor from January 2002 to December 2012 (Japan Meteorological Agency, 2013), the recorded-highest atmospheric temperature of $37^{\circ} \mathrm{C}$ overlapped with the recorded-lowest humidity of $5 \%$ was applied. Forest fire intensity and smoke transport are sensitive to wind conditions so that the sensitivity studies were performed for the PWS of 11.6/7.8/4.7 m/s which are hourly mean wind speeds and their appearance frequencies are 99/90/50 percentiles, respectively. The hourly mean wind speed is suitable for the simulations because a duration of a forest fire is normally in a range of hours-to-days. The high hourly mean wind speed (i.e. $11.6 \mathrm{~m} / \mathrm{s}$ ) covers typical wind speeds during forest fires in Japan (JNES, 2012). The "wind direction" was conservatively set so that an NPP site becomes in the leeward direction from the forest fire breakout point described later. The other weather parameters were set conservatively: i.e. zero cloud cover ratio and zero precipitation. The topographical data with a fine resolution of $10 \times 10 \mathrm{~m}$ (Geospatial Information Authority of Japan, 2013) and vegetation data (Ministry of Land, Infrastructure, Transport and Tourism, 2013) around the studied region were applied to deal with in detail the local forest fire propagation behavior according to the previous studies (Okano and Yamano, 2015). The forest fire breakout point was selected based on the forest fire assessment guide (Nuclear Regulation Authority, 2013) considering a topographical feature and land use in the region. Namely, a forest road end, which is located south-east of the NPP with around $2.5 \mathrm{~km}$ distance, was selected as a forest fire breakout point due to a relation with human activities.

\subsection{Summary of simulation results}

Figures 4 (a) to (c) depict the simulation results by FARSITE for the PWSs of 11.6/7.8/4.7 m/s, respectively. A forest fire propagates while keeping of a similar shape to a concentric circle with some deformation due to topographic effects (e.g. slope angle). The reaction intensity, fireline intensity, spread rate and frontal fireline location were evaluated at each time step of the simulations which depend on forest tree type, local slope angle, and wind direction and speed. The output parameters averaged by the elapsed time from the forest fire breakout to the arrival at the NPP site near to the distance of 500 meters are summarized in Table 1. The reaction intensity is almost the same $\left(9.6 \times 10^{2}\right.$ to $\left.9.7 \times 10^{2} \mathrm{~kW} / \mathrm{m}^{2}\right)$ among the cases because it depends on the vegetation and not on the wind condition. The fireline intensity varies around 1.4 
times $\left(0.85 \times 10^{2}\right.$ to $\left.1.2 \times 10^{2} \mathrm{~kW} / \mathrm{m}\right)$ because it depends on reaction intensity and forest fire spread rate which varies with the PWS. The spread rate varies around 1.5 times $(0.44$ to $0.65 \mathrm{~m} / \mathrm{min}$.) when changing the PWS of around 2.5 times (4.7 to $11.6 \mathrm{~m} / \mathrm{s}$ ), and accordingly the duration of a forest fire spread after the breakout until the arrival at the NPP site is shortened (63 to 43 hours).

Table 1 Input weather conditions, summary of outputs of forest fire propagation simulation by FARSITE, particle matter transport simulations by ALOFT-FT, and cumulative calculation of total amount of particle matters. Prevailing wind speed of 11.6/7.8/4.7 m/s corresponds appearance frequency of 99/95/50 percentiles, respectively.

\begin{tabular}{|c|c|c|c|c|c|c|c|c|c|c|c|c|c|}
\hline \multirow[b]{3}{*}{ Case } & \multirow{2}{*}{\multicolumn{3}{|c|}{$\begin{array}{c}\text { Input Weather Conditions } \\
\text { Prevailing values, } \\
\text { Constant during the simulations }\end{array}$}} & \multicolumn{4}{|c|}{ FARSITE Outputs } & \multicolumn{3}{|c|}{ ALOFT-FT Outputs } & \multicolumn{3}{|c|}{ Cumulative Outputs } \\
\hline & & & & on leewa & $\begin{array}{l}\text { eraged val } \\
\text { line from } b\end{array}$ & $\begin{array}{l}\text { es at frontal } \\
\text { eakout to fir }\end{array}$ & $\begin{array}{l}\text { ireline } \\
\text {-arrival* points }\end{array}$ & $\begin{array}{l}\text { Peak PM } \\
\text { filter heig }\end{array}$ & spatial der & $\begin{array}{l}\text { sity at air } \\
\text { forest fire }\end{array}$ & $\begin{array}{l}\text { Cumulati } \\
\text { from bre }\end{array}$ & amount & $\begin{array}{l}\text { air filter, } \\
\text { arrival }^{*}\end{array}$ \\
\hline & $\begin{array}{l}\text { Wind } \\
\text { speed } \\
{[\mathrm{m} / \mathrm{s}]}\end{array}$ & $\begin{array}{c}\text { Tempera- } \\
\text { ture } \\
{\left[{ }^{\circ} \mathrm{C}\right]}\end{array}$ & $\begin{array}{c}\text { Relative } \\
\text { Humidity } \\
{[\%]}\end{array}$ & $\begin{array}{l}\text { Reaction } \\
\text { intensity } \\
{\left[\mathrm{kW} / \mathrm{m}^{2}\right]}\end{array}$ & $\begin{array}{l}\text { Fireline } \\
\text { intensity } \\
{[\mathrm{kW} / \mathrm{m}]} \\
\end{array}$ & $\begin{array}{l}\text { Spread } \\
\text { rate } \\
\text { [m/min.] }\end{array}$ & $\begin{array}{c}\text { Duration until } \\
\text { fire arrival } \\
\text { [hour] }\end{array}$ & $\begin{array}{l}\mathrm{PM} 2.5 \\
{\left[\mathrm{mg} / \mathrm{m}^{3}\right]}\end{array}$ & $\begin{array}{l}\mathrm{PM} 10 \\
{\left[\mathrm{mg} / \mathrm{m}^{3}\right]}\end{array}$ & \begin{tabular}{|c|} 
Total \\
PMs \\
{$\left[\mathrm{mg} / \mathrm{m}^{3}\right]$} \\
\end{tabular} & $\begin{array}{c}\text { PM2.5 } \\
{[\mathrm{kg}]}\end{array}$ & $\begin{array}{l}\text { PM10 } \\
{[\mathrm{kg}]}\end{array}$ & $\begin{array}{l}\text { Total } \\
\text { PMs } \\
{[\mathrm{kg}]} \\
\end{array}$ \\
\hline 1 & 11.6 & 37 & 5 & $\begin{array}{l}\times 10^{2} \\
9.6\end{array}$ & $\begin{array}{l}\times 10^{2} \\
1.2\end{array}$ & 0.65 & 43 & 0.45 & 0.53 & 0.97 & 5.4 & 6.4 & 12 \\
\hline 2 & 7.8 & 37 & 5 & 9.6 & 0.93 & 0.51 & 55 & 0.15 & 0.18 & 0.33 & 2.3 & 2.8 & 5.2 \\
\hline 3 & 4.7 & 37 & 5 & 9.7 & 0.85 & 0.44 & 63 & 0.017 & 0.020 & 0.037 & 0.18 & 0.22 & 0.40 \\
\hline
\end{tabular}

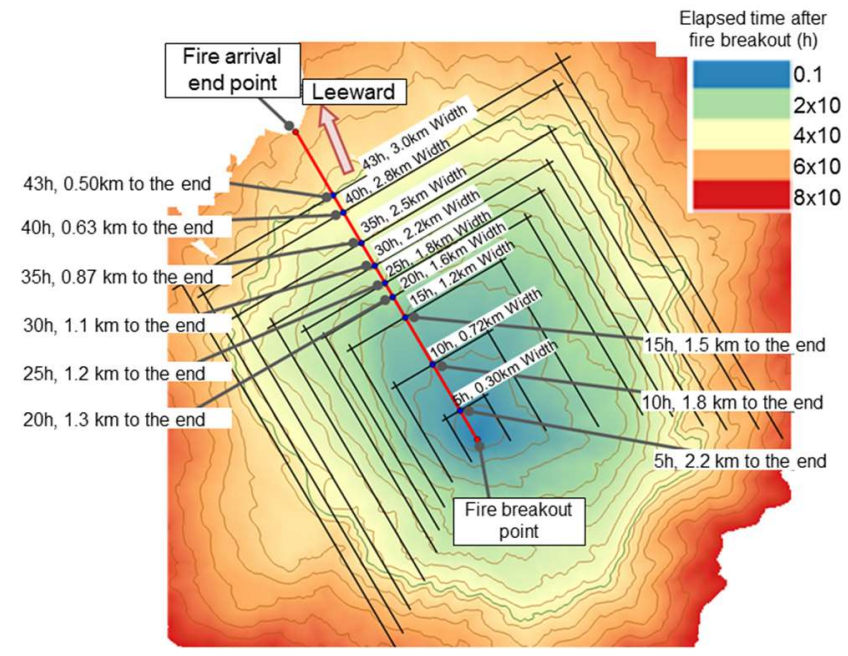

(a) Prevailing wind speed $=11.6 \mathrm{~m} / \mathrm{s}$

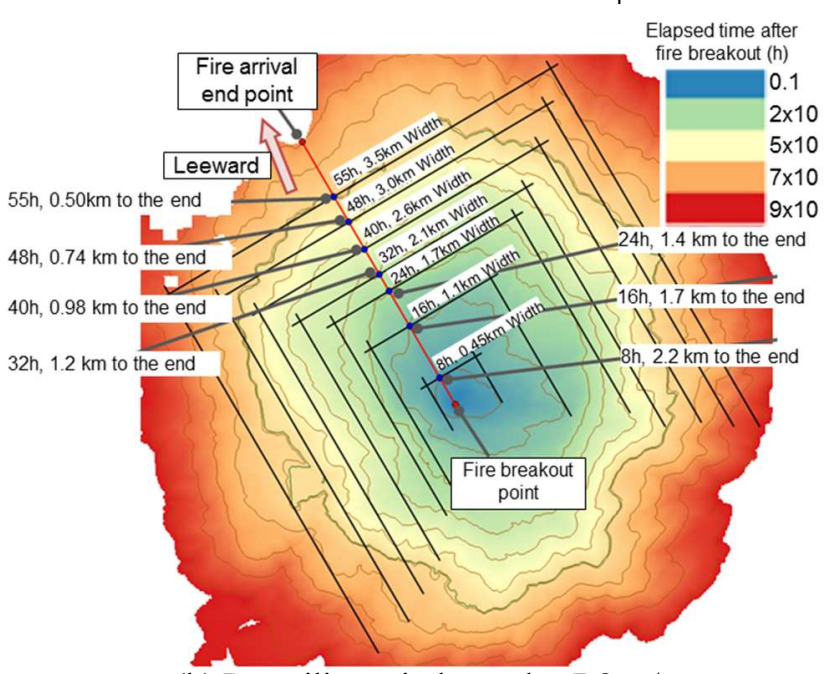

(b) Prevailing wind speed $=7.8 \mathrm{~m} / \mathrm{s}$

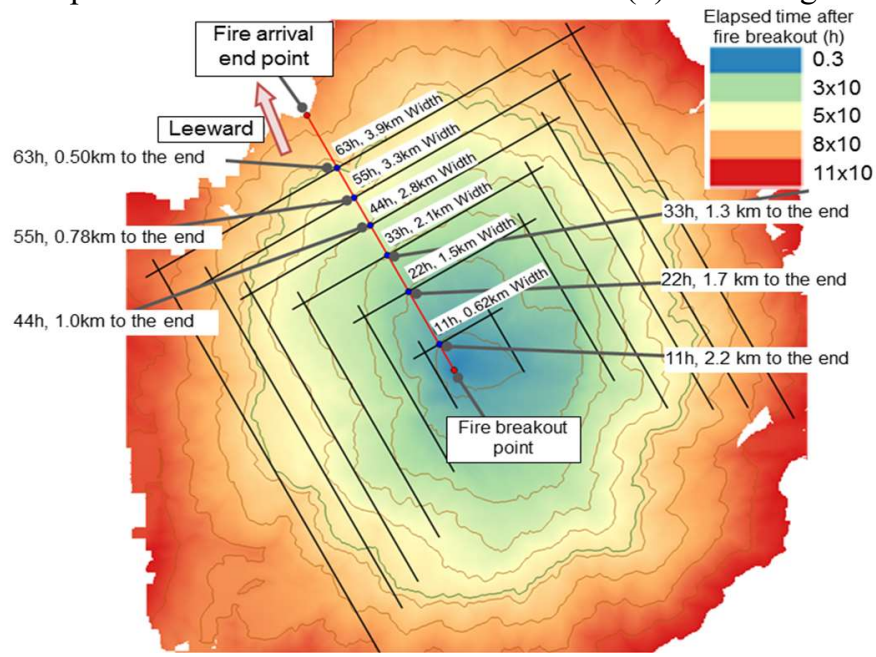

(c) Prevailing wind speed $=4.7 \mathrm{~m} / \mathrm{s}$

Fig. 4 Temporal change of frontal fireline location for the prevailing wind speed of $11.6 / 7.8 / 4.7 \mathrm{~m} / \mathrm{s}$. The depicted maps are magnified to about $5 \mathrm{~km} \times 5 \mathrm{~km}$ area. Light-colored solid lines show frontal fireline propagation at each elapsed time after the breakout. The breakout point is a forest fire road end. The leeward prevailing wind is assumed from the breakout point to the plant. Distances to the end point and crosswise widths of frontal fireline are noted. 


\section{Smoke transport simulations \\ 4.1 ALOFT-FT simulations and initial/boundary conditions}

ALOFT-FT is applied to flat terrain and calculates particle migration generated from a single large fire. It is originally based on a combination of numerical modeling and large scale experimentation yielded by an amount of information about the structure, trajectory and composition of smoke plumes from large crude oil fires. Two Navier-Stokes equations are solved numerically - one is for fire plume rising and another is for plume transport. PMs which are advected in fireinduced flow field are dealt with by Lagrangian method. Although simplified models are applied in ALOFT-FT in comparison with a computational fluid dynamics code, it is utilized to predict the relative change of the PM concentrations on the downwind distribution.

The heat release rate and reaction rate of the forest fire area are necessary to be input to ALOFT-FT. In this study, the "snapshot" outputs of "reaction intensity", "fireline intensity", and "frontal fireline location" evaluated by the sensitivity analyses by FARSITE were utilized as the input data for ALOFT-FT, whereas the active forest fire area along the frontal fireline where the smoke production and the fire plume are active is necessary to be modeled. The snapshotted time steps from the FARSITE results are selected to follow the forest fire spread behavior starting from the forest fire breakout point to the end point. At the final step of the method, temporal changes of a particle concentrations, which are evaluated by ALOFT-FT, at the air filter height of the NPP location is cumulatively summarized to evaluate the total amount of PM captured on the air filter.

\subsection{Models for active forest fire area for smoke production}

Fireline intensity of FARSITE output is directly utilized in ALOFT-FT, whereas temporal change of active fire area is needed to be modeled to be evaluated from the FARSITE outputs. The forest fire intensity parameters are reaction intensity $\left(I_{R}\right.$, unit in $\left.\mathrm{kW} / \mathrm{m}^{2}\right)$ and fireline intensity $\left(I_{L}\right.$, unit in $\left.\mathrm{kW} / \mathrm{m}\right)$ defined by Rothermel's model (1972). The active horizontal flame depth of the frontal fire $\left(D_{A C}\right.$, unit in $\left.\mathrm{m}\right)$ is described using reaction intensity and fireline intensity (Alexander, 1982) by Eq. (1).

$$
I_{R} \equiv I_{L} / D_{A C}
$$

The FARSITE output shows temporal progression of the frontal fireline location in the calculation terrain, and the representative $D_{A C}$ is evaluated from the $I_{R}$ and the $I_{L}$ on the leeway straight lines from the breakout point to the NPP as shown in red straight lines in Figs. 4 (a) to (c). The crosswise width $\left(L_{B}\right.$, unit in $\mathrm{m}$ ) of the frontal fireline circumference boundary, depicted in Figs. 4 (a) to (c), is scanned from the FARSITE outputs. The area of the active forest fire area $\left(S_{A F}\right.$, unit in $\mathrm{m}^{2}$ ) is estimated in this study by Eq. (2).

$$
S_{A F}=L_{B} \times D_{A C}
$$

The $I_{L}$ in the leeway direction is higher than those of crosswind and windward directions due to the prevailing wind; for example, $I_{L}$ in leeway is around one order higher than that in windward. The $D_{A C}$ evaluated by Eq. (1) is, hence, conservative for representing the active forest fire area; on the other hand the $L_{B}$ used in Eq. (2) is shorter than the periphery length (e.g. around 1/4). A weight of flammables per unit area is set to be $2.246 \mathrm{~kg} / \mathrm{m}^{3}$ from the weight of fallen leaves of broad-leaved trees per unit area (JNES, 2012), PM2.5 and PM10 emission ratios from forest trees are respectively given as $5.7 \mathrm{~g} / \mathrm{kg}$ and $7.0 \mathrm{~g} / \mathrm{kg}$ (Johnson and Miyanishi, 2001) for dry fuel condition, and atmospheric stability is conservatively set as $C$ level for surface wind above $6 \mathrm{~m} / \mathrm{s}$ and strong incoming solar radiation in day time (McGrattan, et al., 1997). The time-dependent change of PM density at the site, $\rho_{P M}$ (unit in $\mathrm{g} / \mathrm{m}^{3}$ ) is obtained by ALOFTFT, and the cumulative amount of intake air of the DHRS is simply estimated from the assumptions for air filer surface area $\left(S_{A F}, 18 \mathrm{~m}^{2}\right)$ and the intake air velocity through the air filter $\left(V_{A F}, 10 \mathrm{~m} / \mathrm{s}\right)$. Therefore, the total amount of PM captured on the air filter ( $M_{P M}$, unit in $\left.\mathrm{g}\right)$ is evaluated by Eq. (3). 


$$
M_{P M}=\int\left(\rho_{P M} \times S_{A F} \times V_{A F}\right) d t
$$

The result of this study is conservative from the viewpoint of PM amount, even though there is a restriction of ALOFTFT that it simulates transport phenomena on a flat terrain and it cannot deal with locally unleveled ground effects. This is because the smoke plume drifts upward due to upward convection by a forest fire although the NPP is located in a basin surrounded by hills and facing the sea, and the smoke plume by the forest fire is likely to pass above the site.

\subsection{Simulation result of ALOFT-FT}

The PM10 spatial distribution for the PWS $11.6 \mathrm{~m} / \mathrm{s}$ and at 20 hours after the fire breakout is shown in Fig. 5. The PM quickly rises to around 100-200 meters high even under strong wind conditions due to the hot plume generated by a forest fire and hot air upward drafting. Travel of the PM to the leeward side is mainly by the wind advection, and lateral advection to the wind direction is relatively small so that the crosswise width is only around 100-200 meters. Normally, air intake height of the DHRS is several tens of meters at the highest. For these reasons, the PM density at the air filter becomes lower than that in the main stream line. The peak spatial densities of PM2.5 and PM10 become $0.45 \mathrm{mg} / \mathrm{m}^{3}$ and $0.53 \mathrm{mg} / \mathrm{m}^{3}$, respectively, and the total becomes $0.97 \mathrm{mg} / \mathrm{m}^{3}$ as shown in Table 1. It is below the authorized warning of air pollution, $2 \mathrm{mg} / \mathrm{m}^{3}$ (Government decree, 1968), for one hour average density of a suspended PM, although above the environmental quality standard for air pollution, $0.20 \mathrm{mg} / \mathrm{m}^{3}$ (Ministry of the Environment, 1973). Accident management actions such as a forest fire fighting in/near the NPP site for several hours is therefore feasible under these smoke density conditions.

The cumulative amount of PM captured on the air filter for PWS of 11.6/7.8/4.7 m/s is shown in Fig. 6. It increases with the PWS, and it was evaluated to be around $5.4 \mathrm{~kg}$ and $6.4 \mathrm{~kg}$ at the most for PM2.5 and PM10 respectively. This means that PM weight per unit area of the filter is around $0.65 \mathrm{~kg} / \mathrm{m}^{2}$ (i.e. $[5.4 \mathrm{~kg}+6.4 \mathrm{~kg}] / 18 \mathrm{~m}^{2}$ ) and it is far below the operational limit of the air filter, i.e. around $15 \mathrm{~kg} / \mathrm{m}^{2}$ as a design basis. It was concluded that the PMs do not affect the integrity of the air filters of the DHRS.
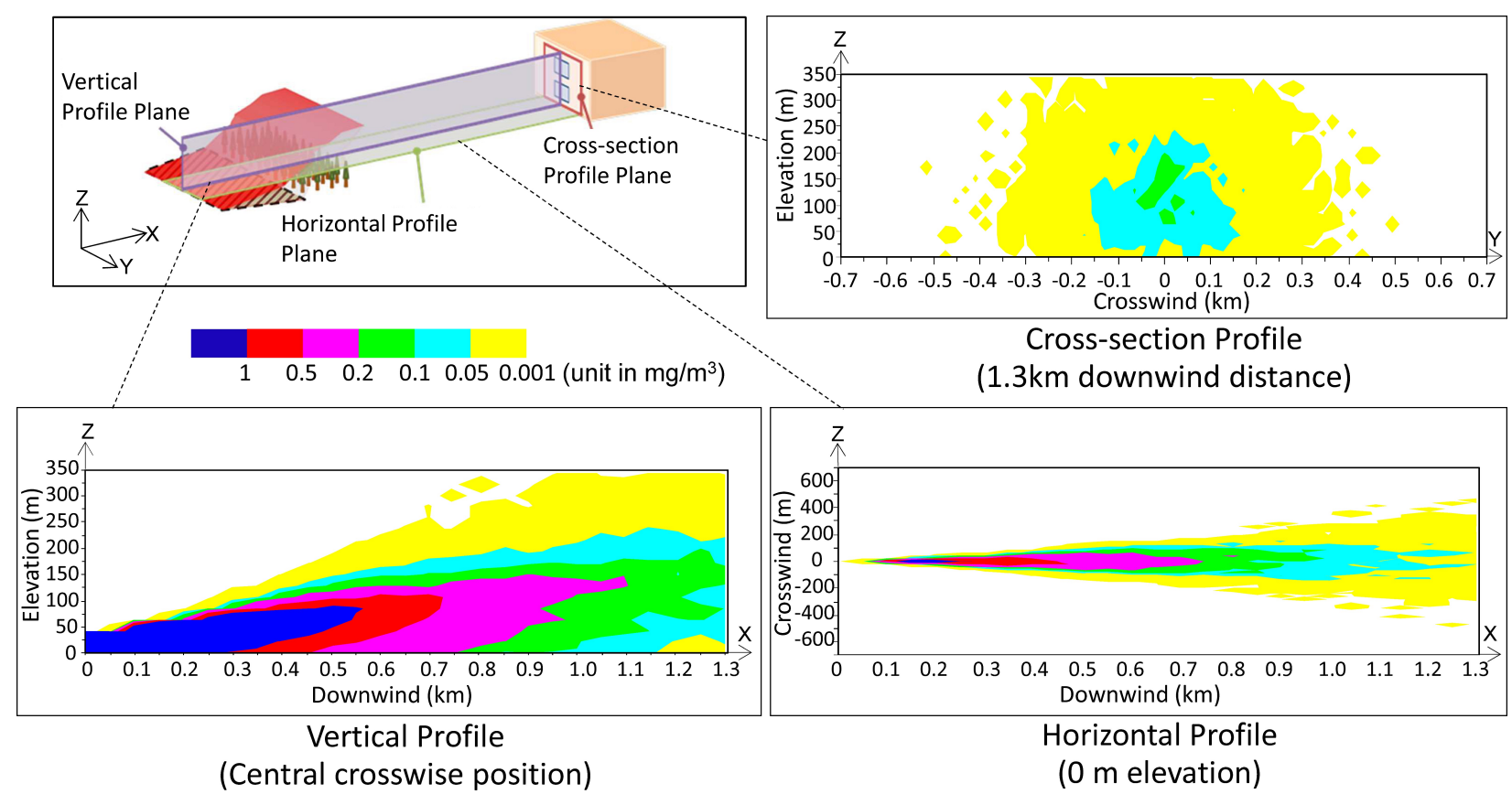

Fig. 5 Contours of PM10 spatial density distributions as an ALOFT-FT simulation result. The simulation conditions were the prevailing wind speed of $11.6 \mathrm{~m} / \mathrm{s}$ and 20 hours after the forest fire breakout. Vertical and cross-section profiles show that the main stream is declined due to the leeward wind, and the smoke plume reaches to the elevation of 100-200 meters, whereas the crosswise width is relatively narrow around 100-200 meters even in the $1.3 \mathrm{~km}$ downwind distance. 


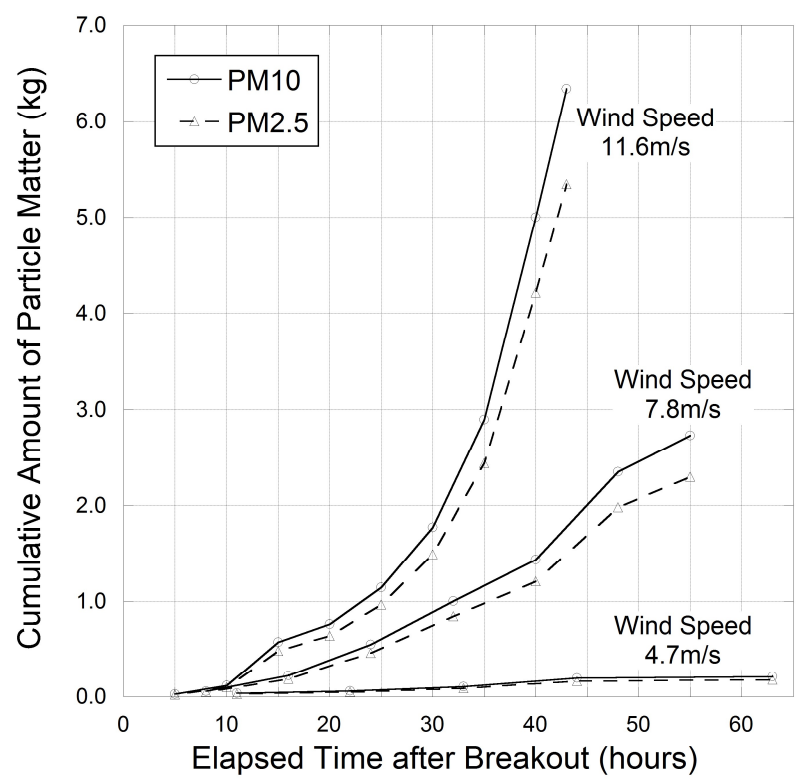

Fig. 6 Cumulative PM2.5 and PM10 amounts on air filters for the prevailing wind speed of 11.6/7.8/4.7 m/s. The characteristics parameters of a decay heat removal system were assumed to be an air filter area of $18 \mathrm{~m}^{2}$ and intake air velocity of $10 \mathrm{~m} / \mathrm{s}$. The cumulative amounts of PM2.5 and PM10 from the breakout until the forest fire arrives at the nuclear power plant increase with the prevailing wind speed, and they become at the most around $5.4 \mathrm{~kg}$ and $6.4 \mathrm{~kg}$, respectively, for the prevailing wind speed of $11.6 \mathrm{~m} / \mathrm{s}$.

\section{Discussions on wind effects on forest fire spread and PM transport}

Figure 7 (a) depicts the simulation results by FARSITE on frontal fireline crosswise width (unit in km) and distance from the frontal fireline location to the end point near the NPP site (unit in km) for the wind speeds of 11.6/7.8/4.7 m/s. Even with variety of wind speed, the frontal fireline crosswise width increases nearly the same because the leeward wind makes little effect on the crosswise forest fire propagation. On the other hand, the higher the wind speed becomes, the more accelerated the forest fire propagation in the leeward direction, thus the residual distance to the end point decreases faster. This means that, when wind speed is higher, the forest fire spread area shape on the terrain is stretched further and the circumference length of the forest fire spread area becomes larger due to the elongation to leeward.

The active forest fire areas are shown in Fig. 7 (b). The higher wind speed makes quicker increase of the area because of higher fireline intensity that results in the increase of the active forest fire area. The lines in Fig. 7 (b) do not show simple uniform increase because the fireline intensity, and accordingly the active forest fire area by Eqs. (1) and (2), is affected by not only PWS but also local slope angle and local vegetation at which the frontal forest fireline is located. The range of the areas of the three cases of $11.6-4.7 \mathrm{~m} / \mathrm{s}$ is in nearly the same level (around $0.5 \times 10^{2} \mathrm{~m}^{2}$ ) initially and has around 1.3 times difference (around $4.0 \times 10^{2}-5.6 \times 10^{2} \mathrm{~m}^{2}$ ) even at the timing of the end points. The reaction intensities of three cases are nearly the same level (around $9.6 \times 10^{2} \mathrm{~kW} / \mathrm{m}^{2}$ ) and the frontal fireline intensity has only around 1.4 times difference (around $0.85 \times 10^{2}-1.2 \times 10^{2} \mathrm{~kW} / \mathrm{m}$ ) as shown in Table 1 .

The cumulative amount of PM for three PWS cases varies widely from $0.4 \mathrm{~kg}$ to $12 \mathrm{~kg}$ (i.e. around 30 times) for PWS of $4.7 \mathrm{~m} / \mathrm{s}$ to $11.6 \mathrm{~m} / \mathrm{s}$ respectively as shown in Table 1 and Fig. 6 . The reason why such a large difference is made, even that the active forest fire area and fireline intensity are only 1.3-1.4 times different, is due to the PM transport behavior in spatial domain especially in elevation vs. leeward transport. Isolines of PM10 density of $0.2 \mathrm{mg} / \mathrm{m}^{3}$ for PWSs of 11.6/7.8/4.7 m/s are depicted in Fig. 8, at the timing when the frontal fireline is at $1 \mathrm{~km}$ away from the end point. The arrival height of PM main stream is around a few hundred meters in all the three cases, whereas the height of air stack of the DHRS is around several tens meters for example so that the main PM stream paths are far above the air stack. The PMs are transported to lower altitude in the leeward side under the high PWS of $11.6 \mathrm{~m} / \mathrm{s}$ than that of low PWS of $4.7 \mathrm{~m} / \mathrm{s}$. For the PWS of $7.8 \mathrm{~m} / \mathrm{s}$, the PM transport behavior is between the high and low PWS cases. Then, the cumulative amount of PM captured on air filter becomes significantly high under the high PWS case. 


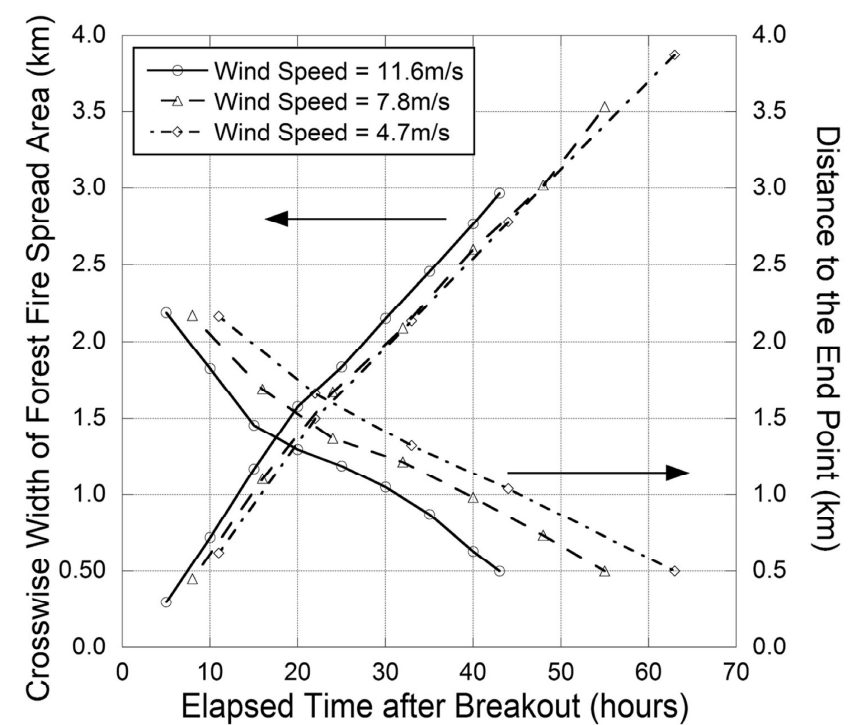

(a) Crosswise width and distance to the end point

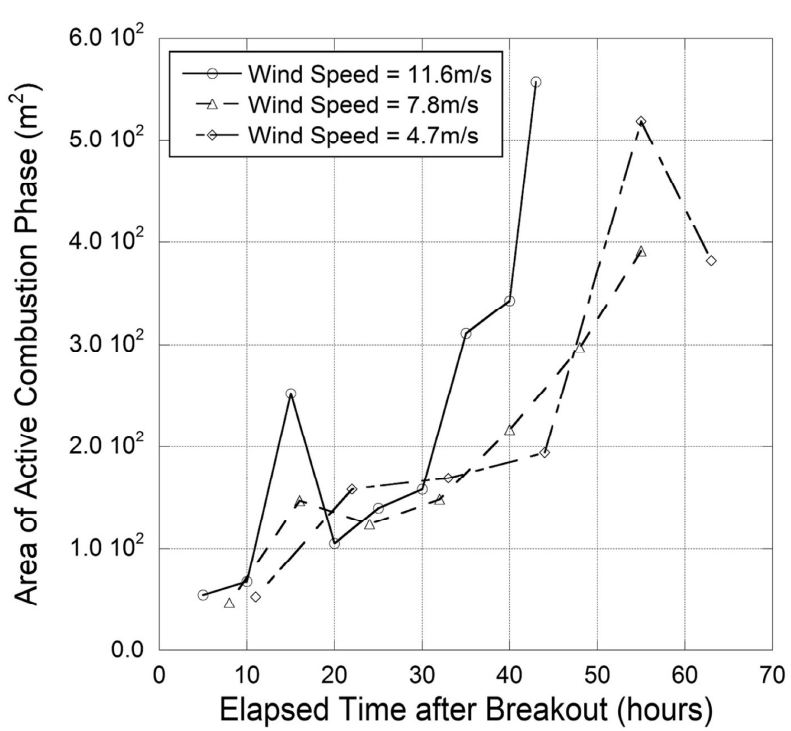

(b) Active forest fire area

Fig. 7 Forest fire spread behavior and change of active forest fire area. The left figure shows the changes of crosswise width of forest fire spread area and distance to the end point (i.e. boundary of a nuclear power plant site) with the elapsed time after the breakout. The right figure shows the changes of the area of active forest fire zone along the periphery boundary of forest fire spread area with the elapsed time after the breakout. In both figures, the solid, chain and dashed lines represent the prevailing wind speed of 11.6/7.8/4.7 m/s, respectively.

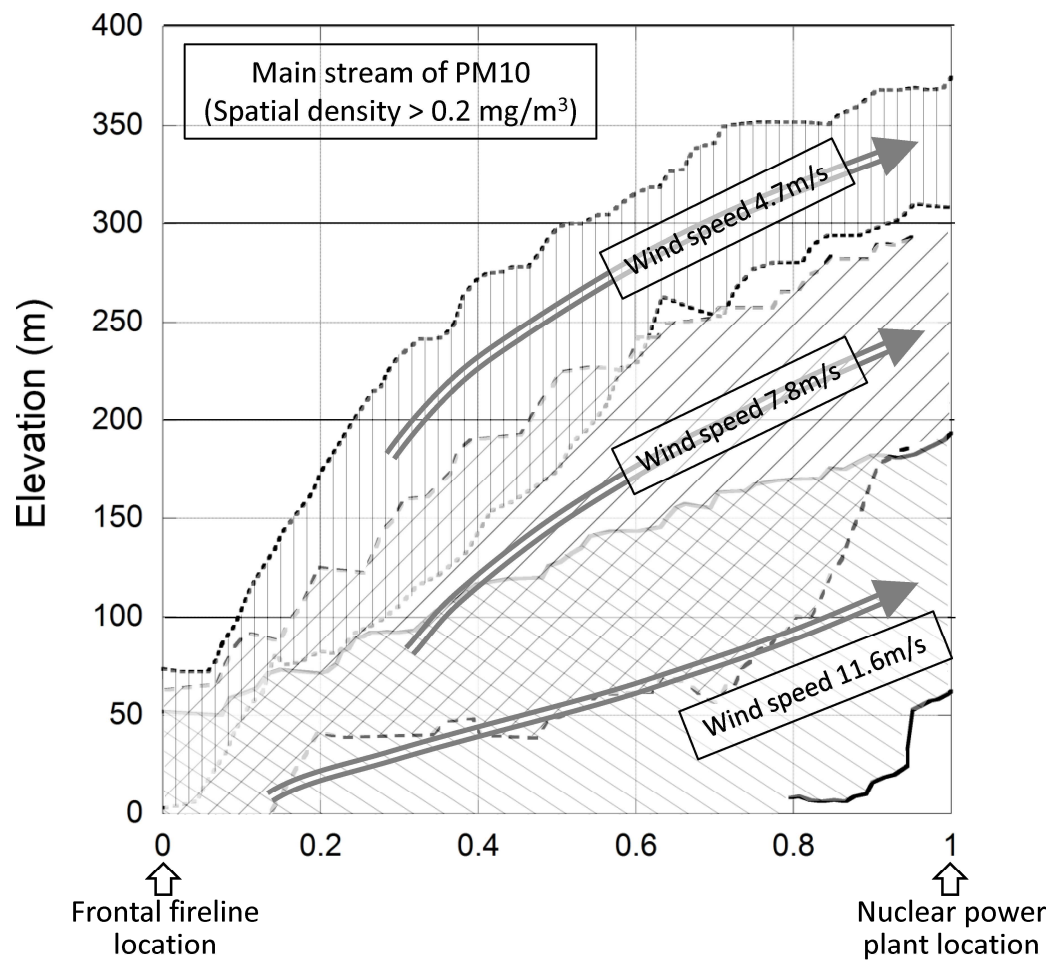

Distance from Frontal Fireline $(\mathrm{km})$

Fig. 8 Schematic of vertical transport behavior of particle matter for the prevailing wind speed of 11.6/7.8/4.7 m/s. The areas drawn with diagonal lines represent PM10 density above $0.2 \mathrm{mg} / \mathrm{m}^{3}$, at the timings of frontal fireline location around $1 \mathrm{~km}$ away from the nuclear power plant site. Arrowed lines indicate main smoke stream paths which are drifted by the forest fire plume and horizontally advected by the prevailing wind. 


\section{Conclusions}

The forest fire smoke is one of potential challenges for an NPP. Especially for a sodium-cooled fast reactor system, the ultimate heat sink for decay heat removal under accident condition is ambient air so that quantitative assessment on smoke effect is one of key issues on safety. The new method was developed in this study where PM transport simulation by ALOFT-FT, with combinational utilization of FARSITE results, is applied to evaluate the smoke spatial density in an NPP and the cumulative amount of PM on the air filter is evaluated. The PM density during a forest fire reaches around $1 \mathrm{mg} / \mathrm{m}^{3}$ which is lower than the authorized warning of air pollution so that accident managements related to a forest fire would be feasible in an NPP site. The total amount of PM on the air filter of the DHRS is less than $1 \mathrm{~kg} / \mathrm{m}^{2}$ which is well below the operational limit of the air filter of $15 \mathrm{~kg} / \mathrm{m}^{2}$.

While this study focuses on the challenge by smoke which would potentially affect a sodium-cooled fast reactor, the method developed in this study can be applied for equipment of other NPPs which may be affected by forest fire smoke with taking into account specific topographical condition in the forest fire propagation simulations by FARSITE.

\section{Acknowledgments}

This study is the result from "Research and Development of Margin Assessment Methodology of Decay Heat Removal Function against External Hazards" entrusted to Japan Atomic Energy Agency by the Ministry of Education, Sports, Science and Technology (MEXT) under Grant System/120802. The authors wish to thank Mr. J. Masuzawa, Mr. T. Inoue, and Mr. Y. Kitamura of Mitsubishi Research Institute, Inc. on the forest fire simulations, and Mr. K. Yamashita of the Forest Fire Control Association and Mr. Y. Goto of the Forestry and Forest Products Research Institute for general advices related to a forest fire and forestry.

\section{References}

Alexander, M. E., Calculating and interpreting forest fire intensities (1982), Canadian Journal of Botany, Vol. 60, pp.349358.

Finney, M. A., FARSITE: Fire Area Simulator - Model Development and Evaluation (2004), RMRS-RP-4 Revised, United States Department of Agriculture.

Forest Fire Control Association, Practical guide of managements on forest and field fires (2007), p.23, Japan Forest Foundation.

Geospatial Information Authority of Japan, Fundamental Geospatial Data (online), available from $<$ http://www.gsi.go.jp/kiban/>, (accessed on 30 September 2013) (in Japanese).

Government decree, Enforcement order on air pollution control raw (1968), Article 11, Appendix Table 5 (in Japanese).

Japan Meteorological Agency, Automated Meteorological Data Acquisition System (AMeDAS) (online), available from $<\mathrm{http} / / / w w w . j m a . g o . j p / j p / a m e d a s />$, (accessed on 30 September 2013) (in Japanese).

JNES (Japan Nuclear Energy Safety Organization), Wild Fire evaluation for Fukushima Daiichi Nuclear Power Plant (2012), JNES-RC-2012-0002, Table 2.2 in p.2-2, Table 2.3 in p.2-3, and Table B-7 in p.45.

Johnson, E.A. and Miyanishi, K., Forest Fires, behavior and ecological effects (2001), p.74, Academic Press.

Kochanski, A. K., D. B. Jonathan, Mandel, J. and Clements, C. B., Air pollution forecasting by coupled atmosphere-fire model WRF and SFIRE with WRF-Chem, Proceedings of $4^{\text {th }}$ Fire Behavior and Fuels Conference (2013), pp. 143155, International Association of Wildland Fire.

McGrattan, K. B., Putorti, A. D., Twiliey, W. H. and Evans D. D., Smoke Plume Trajectory from In Situ Burning of Crude Oil in Alaska (1993), NISTIR 5273, National Institute of Standards and Technology.

McGrattan, K. B., Baum, H. R., Walton, W. D. and Trelles J., Smoke Plume Trajectory from In Situ Burning of Crude Oil in Alaska --- Field Experiments and Modeling of Complex Terrain (1997), NISTIR 5958, National Institute of Standards and Technology, Table 6, p.23.

Ministry of Land, Infrastructure, Transport and Tourism, National Land Numerical Information, available at $<$ http://nlftp.mlit.go.jp/ksj-e/index.html>, (accessed on 30 September 2013).

Ministry of the Environment, Environmental standards on air pollution (1973), Article 1, Appendix Table (in Japanese). Nuclear Regulation Authority, Guide for assessment on external fire accidents (draft) (2013), Appendix A, p.3 (in 
Japanese).

Nuryanto, D. E., Simulation of forest fires smoke using WRF-Chem model with FINN fire emissions in Sumatera (2015), Procedia Environmental Sciences, Vol. 24, pp.65-69.

Okano, Y. and Yamano, H., Development of Margin Assessment Methodology of Decay Heat Removal Function against External Hazards (3) Forest Fire Hazard Assessment Methodology, Proceedings of $10^{\text {th }}$ International Topical Meeting on Nuclear Thermal Hydraulics, Operation and Safety (NUTHOS-10) (2014), Paper No.1018.

Okano Y and Yamano H., "Forest fire propagation simulations for a risk assessment methodology development for a nuclear power plant”, Case Studies in Fire Safety, Vol.4 (2015), pp.1-10, DOI:10.1016/j.csfs.2015.05.001.

Pouliot, G., Pierce, T., Benjey, W., O’Neill, S. M. and Ferguson, S. A., Wildfire Emission Modeling: Integrating BlueSky and SMOKE, Proceedings of $14^{\text {th }}$ International Emission Inventory Conference (2005), U.S. Environmental Protection Agency.

Rothermel, R.C., A Mathematical Model for Predicting Fire Spread in Wildland Fuels (1972), USDA Forest Service, Research Paper INT-115.

Rouil L., Impact of in situ burning on air quality (2015), 20 th Cedre Information Day, available from $<$ http:// http://wwz.cedre.fr/en/content/download/8118/129184/file/2-ineris-impact-brulage-in-situ-ENG.pdf>, (accessed on 10 October 2015).

Sandberg, D. V.; Ottmar, R. D.; Peterson, J. L. and J. Core, Wildland fire on ecosystems: effects of fire on air (2002), General Technical Report RMRS-GTR-42-vol. 5, US Department of Agriculture, Forest Service, p.39.

Trentmann, J. Luderer, G., Winterrath, T., Fromm, M. D., Servranckx, R., Textor, C., Herzog, M., Graf, H. F. and Andreae, M. O., Modeling of biomass smoke injection into the lower stratosphere by a large forest fire (Part I): reference simulation (2006), Atmospheric Chemistry and Physics, Vol. 6, pp.5247-5260.

Vairo, T., Pastorino, R., Rehman, A. and Fabiano B., An Approach to Risk Evaluation in Connection with Fire Scenarios from a Cruise Ship (2015), Chemical Engineering Transactions, Italian Association of Chemical Engineering, Vol. 43, pp. 1939-1944, DOI: 10.3303/CET1543324.

Yamada, T., Smoke Plume Trajectory from In-Situ Burning of Crude Oil in Tomakomai -Field Experiments and Prediction with ALOFT-PC- (1998), Book of Abstracts of Annual Conference on Fire Research, NIST 6242, pp.9596. 